\title{
A bird in the hand Free online ornithological resources
}

W hile popular depiction of birders fuels the stereotype of a birder as raritychasing and highly competitive, the skill level and approach of this population is highly diverse. From novice to advanced birder, backyard-based to international traveler, the number of people who view or photograph birds has grown considerably over the last several decades. ${ }^{1}$ In the United States, more than 80 million people-the combined population of California, Florida, and New York —watch birds. ${ }^{2}$

Not only are more people watching birds than ever before, but more people are engaging in structured observational projects. Citizen scientists are contributing millions of datum and expanding the definition of scientist. Access to projects across the globe encourage observers to add to crowdsourced datasets, and allows scientists of all ages to participate. The Christmas Bird Count, sponsored by the National Audubon Society, is the longest-running citizen science project in the country. Each year, tens of thousands of people count birds during a three-week time frame, and the data from these group efforts informs policy and conservation efforts. ${ }^{3}$

Scientists and researchers of all backgrounds use online resources to report their findings, study their subjects, and connect with each other. The following Internet resources have been picked for ease of use, depth of content and ability to be used without cost to the user, and are divided into four categories: open access scholarly research and books; government and nonprofit publications and data sets; blogs, email lists, and wikis; and multimedia. The wide variety of citizen science projects, however, is beyond the scope of this research-oriented list.

\section{Open access scholarly research and books}

- Biodiversity Heritage Library (BHL). Headquartered at Smithsonian Libraries, this collection has digitally ingested more than 36,000 titles from its 17 -member consortium. Books are made openly available online, and although most of the material is in the public domain and therefore not restricted Biodiversity Heritage Library by copy- www.biodiversitylibrary.org right, many titles here are not indexed by Google Scholar. The standout feature of this collection is the availability of materials in other languages and focus on naturalists of diverse backgrounds. Check out the Latino Natural History collection to see materials about and by naturalists who have influenced science in their home countries

Adrienne Warner is library services coordinator, Reference and Information Services at the University of New Mexico's College of University Libraries and Learning Sciences, email: adriennew@unm.edu

(c) 2015 Adrienne Warner 
and across the globe. Access: http://www. biodiversitylibrary.org.

- Ornithology Exchange. Although membership is encouraged, anyone can browse this ornithologist-compiled wiki. The site highlights news, professional meetings and events, book reviews, and jobs. The Journals section displays a table of journal titles, including the publishing organization, countries covered, years in publication, and a link to the journal's homepage. Users can search for journals by levels of access: open access to all volumes, open access to some volumes, or hybrid open access to some articles. Journal title results may also be geographically limited by country, state, and region. Access: ornithologyexchange.org.

\section{- Searchable Online Research Ar-} chive. The University of New Mexico Libraries developed and host this open access pub-

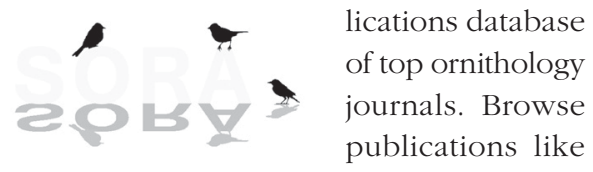
Auk, Condor and Journal of Raptor Research, or search for specific topics or articles. Many articles housed here are unindexed by Google Scholar. Users do not need a user account to browse or download articles, however signing up for a free login allows users to rate and comment on articles, as well as post photographs and documents to the site. Access: https://sora.unm.edu.

\section{Government and nonprofit publications and data sets}

- BirdLife International. This umbrella nonprofit joins 120 conservation nonprofit organizations across the globe and in conservation partnership. In the Science tab, the "Data Zone" provides country profiles that include the number and names of bird species that occur in a selected country, a table of wildlife laws and agreements in effect, and maps of Important Bird Areas. Though slightly labyrinthine to navigate, the breadth of data available at this site is well worth the effort. Access: http://www.birdlife.org/.
- eBird. The synthesis of public-sourced, qualitycontrolled data into a simple interface has propelled eBird into the premier citizen-science ornithology database. Users can search by location, species, abundance, recommended birding "hotspots," and seasonality. Maps and bar charts are easily navigable and customizable. Additionally, eBird automatically generates personalized lists for users who register and input bird sighting data, including yard, county, state, lifetime, and year-to-date lists. Millions of bird sightings have been entered, and anyone, registered or not, may benefit from this massive data source. Access: http://www.ebird.org.

\section{- Global Raptor Information Network} (GRIN). Supported by the nonprofit Peregrine Fund, this site connects professional ornithologists specializing in birds of prey. The Requests for Assistance tab invites researchers to submit explanations of their raptor projects and the type of assistance needed, such as requests for information, sightings, and tissue samples. In addition to this network, GRIN's library offers a robust direct-to-user interlibrary loan service. Click on the Bibliography tab to browse the library's holdings and to request copies of articles and book chapters at no cost. Access: http://www.globalraptors. org/grin/indexAlt.asp.

- National Audubon Society. Started in 1900, the annual Christmas Bird Count project is the longest-running citizen science project, and the data from these counts are available. The most recent count summary lists regional accounts of count circle coverage, noteworthy species encountered, and highlighted numbers for species of conservation concern. For insight into how the data from this project has informed research, click on the Christmas Bird Count Bibliography page. More than 200 citations are listed. Access: https://www. audubon.org/conservation/science/christmas -bird-count.

- Partners in Flight. This nonprofit organization makes large amounts of data available to the general public through its 


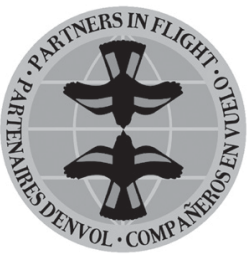

two major databases. The Species Assessment Database is a repository of the organization's data gathered from their own scientific data-collection

process, targeting conservation status, and recommendations for protection. The Population Estimates Database estimates the populations of birds on national, continental, and global scales for every species that occurs in North America (not including shorebirds, water birds, and waterfowl). Population estimates are archived so historical data is also available, which is particularly helpful when analyzing population trends over time. Access: http://www.partnersinflight.org/.

- United States Fish and Wildlife Service Migratory Bird Program. This federal government program aims to protect, restore, and conserve birds across the nation, and has many publications and data sets available. Users may click on the Surveys and Data tab to access population and harvest surveys, and bird banding data The Migratory Bird Data Center page has links to ten other surveys. Included here is the North American Breeding Bird Survey, a project that employs a rigorous data collection protocol, is coordinated by professional Breeding Bird Survey coordinators, and is analyzed closely by researchers and statisticians. This survey informs conservation managers and scientists, and is one component of the influential publication The State of the Birds: United States of America. Access: http:// http://www.fws.gov /birds/index.php.

\section{Blogs, email lists, and wikis}

- American Birding Association

(ABA). This nonprofit organization is dedicated to serving recreational birders, and tools for researchers can be found under the "Publications" tab of the website. An inventory of bird clubs by state offers easily obtainable contact information for local ornithology expertise. Users can then click on "mailing lists" to see links to email lists categorized by state, region, or country. An essential tool for birders in general, email lists are a platform for researchers to request information from the group, and automatically receive emails cov-

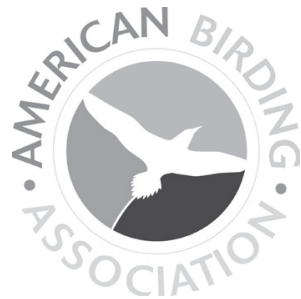
ering timely bird sightings. ABA makes it easy to see which electronic lists are available. Access: http://birding.aba.org /mailinglists.php.

- Dan Tallman's Ornithology Course. Retired ornithology professor Dan Tallman received his Ph.D. from Louisiana State University and has made his undergraduatelevel lecture notes freely available in blog format. Topics are comprehensive and cover everything from origin and evolution to taxonomy, behavior, and ecology. So much information is packed into this blog that one could treat it as a free home study course in ornithology. Access: http://ornithologycourse.blogspot.com/.

- Fatbirder. Self-proclaimed "Fat Birder" Bo Beolens has compiled this easily navigable website whose stand-out feature is a list of bird-related podcasts under the "Sight, Sound and Equipment" tab. Links to the podcasts' webpages are displayed

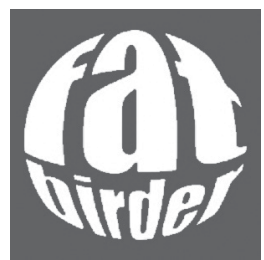
prominently, along with an overview of each podcast. Access: http://fatbirder.com.

- The Multilingual Birdsearch Engine. Common bird names vary by language, and this language translation wiki outstrips Google Translate. Enter a bird's name in one language, and a list of common names appear in other languages. By clicking on the Edit button at the bottom of the page, not only can users edit the wiki, but they can also see the name revision history. This site may be especially helpful for international ornithologists, or those doing research abroad. The stylish, simple design 
facilitates easy use. Access: http://www. knutas.com/birdsearch/.

\section{Multimedia}

- All About Birds. This multimedia website from the Cornell Lab of Ornithology has tips on identifying, watching, and attracting birds; hot

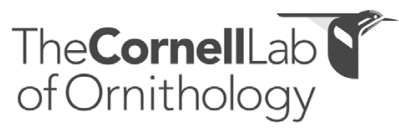

conservation issues; te a ching tools for

youth educators; invitations to join their many citizen science projects; "Inside Birding" how-to videos; and a bevy of real-time bird cams. Friendly and colorful, this website caters to young and seasoned birders alike. Access: http://allaboutbirds.org.

\section{- Louis Agassiz Fuertes Illustration}

Collection. The Cornell University Library's Division of Rare and Manuscript Collections has collected and made electronically available more than 2,500 images of artistnaturalist Louis Agassiz Fuertes. Most of the collection focuses on birds, and users can search by bird name or artistic medium. His drawings, oils, gouaches, watercolors, book plates, and oil paintings are accompanied by metadata, and many of his illustrations were used in early field guides. Excerpts from his 1899 field journal include his poetic descriptions of bird song and plumage, transporting the reader to the days of turn-of-the-century American ornithology. Access: http://cidc. library.cornell.edu/Fuertes2000/fuertes.asp.

- Macaulay Library. The Macaulay Library boasts the largest archive of wildlife sounds and videos, and has recordings of more than $75 \%$ of the world's birds. Users may search for individual species or browse by taxonomy. The "Staff Picks" section highlights personally curated recordings of interest. Professional and amateur audio and video submissions are welcome, and many of their archived sounds have come from citizen scientists. Although sounds may not be freely downloaded, search results metadata may be downloaded as an Excel file. For those looking to purchase an archive of bird sounds, the Macaulay Library has an assortment of regional and continental sets available as digital downloads or preloaded on a USB flash drive. Access: http://macaulaylibrary.org/.

- National Science Digital Library. This website compiles resources for science, technology, engineering, and math educators and students, and users can limit results based on student education level, and resource type (including primary sources, images, audio lectures, and lesson plans). Ornithological search results prominently feature instructions for environmental educational activities, such as how to build bird feeders, dissect owl pellets, and create sound-mimicking devices. Access: http://nsdl.org.

- Xeno-canto. Devoted entirely to bird sounds, this database is maintained by the Netherland's Xeno Canto Foundation. It allows anyone across the globe to listen, download, or add recordings of bird sounds at no cost to the user. Because even the same species of birds have regional dialects and variations in repertoire, this database is particularly useful for location searches, though you can also search by genus, recordist, type of bird sound, recording quality, and recording license. Access: http://www. xeno-canto.org/.

\section{Notes}

1. H. Ken Cordell and United States. 2012. "Outdoor Recreation Trends and Futures: A Technical Document Supporting the Forest Service 2010 RPA Assessment," General technical report SRS, 150; (Asheville, North Carolina: U.S. Dept. of Agriculture, Forest Service, Southern Research Station) http://purl.fdlp.gov/GPO /gpo32237.

2. U.S. Census Bureau, "Annual Estimates of the Resident Populations: April 1, 2010 to July 1, 2014," American FactFinder, http:// factfinder.census.gov/rest/dnldController /deliver?_ts=462645577685 (accessed October 11, 2015).

3. "History of the Christmas Bird Count," Audubon, January 21, 2015 (accessed October 13, 2015). $n$ 